\title{
Study on the interaction of electric vehicle roll and battery pack stability
}

\author{
Yuezhen Fan*, Jie Sun** \\ *School of Technology, Beijing Forestry University, NO.35 Qinghua East Road, Haidian District,100083 Beijing, China, \\ E-mail: fanyuezhen@163.com \\ **School of Technology, Beijing Forestry University, NO.35 Qinghua East Road, Haidian District,100083 Beijing, China, \\ E-mail: $397853042 @ q q . c o m$
}

cross $^{\text {ref }}$ http://dx.doi.org/10.5755/j01.mech.23.1.14059

\section{Introduction}

Battery safety of electric vehicles is important for the application of electric vehicles. The performance of the battery pack determines the development of electric vehicle. Domestic and overseas media have reported electric vehicle explosion accidents so many times. Battery safety of electric vehicles mainly contains three aspects: electrical safety, thermal balance and vibration, the vibration of the battery pack is especially important. Vibration will lead to the declination of battery performance, the change of contact resistance, even the arc and uncontrollable thermal under driving condition. These may cause a fire or an explosion. The performance of battery pack not only depends on the BMS (Battery Management System) that makes the battery pack charges and discharges more reasonably, but depends on the stability of the battery pack. The vehicle steering characteristic is changed because of the ground roughness, and it influences the movement of the battery pack. To improve the ride performance of the vehicle and battery pack, it is essential to study the interaction of electric vehicle roll and battery pack stability [1]-[3].

\section{9-DOF vehicle roll model}

The uneven road can affect the stability of the vehicle body and battery pack. Considering the vehicle yaw velocity and lateral velocity, a 9-DOF vehicle roll model includes the battery pack was developed (Fig. 1) [4, 5]. The 9-DOF as follows: vehicle lateral displacement, vertical displacement, pitch, roll, vehicle yaw velocity, and movement of the vertical direction of four wheels.

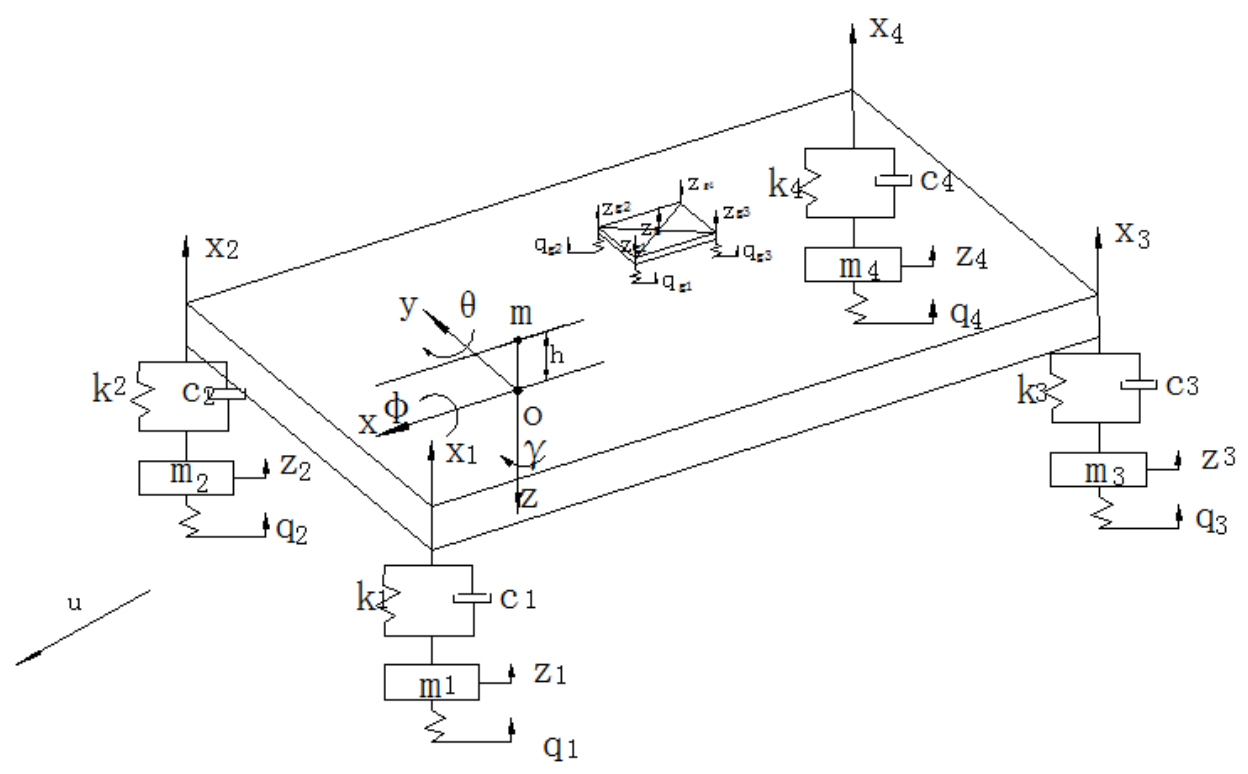

Fig. 1 9-DOF full vehicle roll model

2.1. The lateral acceleration of the vehicle body

The point $O$ is the intersection of vertical line passing through the centroid of vehicle and roll axis. Based on the vehicle coordinate system with the origin at the point $\mathrm{O}$, the centroid position vector with respect to the point $\mathrm{O}$ can be written as [6]-[9]:

$$
P=A_{y}(\theta) A_{x}(\phi)\left[\begin{array}{c}
0 \\
0 \\
-h
\end{array}\right]+\left[\begin{array}{l}
0 \\
0 \\
z
\end{array}\right]=\left[\begin{array}{c}
-h \cos \phi \sin \theta \\
h \sin \phi \\
-h \cos \phi \cos \theta+z
\end{array}\right]
$$

where

$$
A_{x}(\phi)=\left[\begin{array}{ccc}
1 & 0 & 0 \\
0 & \cos \phi & -\sin \phi \\
0 & \sin \phi & \cos \phi
\end{array}\right]
$$




$$
A_{y}(\theta)=\left[\begin{array}{ccc}
\cos \theta & 0 & \sin \theta \\
0 & 1 & 0 \\
-\sin \theta & 0 & \cos \theta
\end{array}\right] .
$$

The relationship of position vector $P$ in inertial system and vehicle coordinate system was obtained by using the instantaneous velocity of the rigid body. It can be expressed as:

$$
\frac{d P^{G}}{d t}=\frac{d P^{S}}{d t}+\omega_{v} P
$$

$G$ is the ground reference system for vehicle motion, $S$ as the body-fixed coordinate frame, the coordinate system of the vehicle has the angular velocity $\omega_{v}=\left[\begin{array}{lll}0 & 0 & r\end{array}\right]^{T}$, and the synthetic velocity $v_{0}=\left[\begin{array}{lll}u & v & 0\end{array}\right]^{T}$. Taking the derivative of the Eq. 2, we can get:

$$
v_{s}=v_{o}+\frac{d P^{G}}{d t}=v_{o}+\frac{d P^{s}}{d t}+\omega_{v} P .
$$

Taking the derivative of the Eq. (3) again and substituting in the formula of acceleration composition, the acceleration of the centroid of the inertial system is obtained.

$$
a_{s}=\frac{d v_{s}}{d t}+\omega_{v} v_{s}
$$

According to Eq. (1) and Eq. (4), the acceleration $a_{s}$ was decomposed in the vehicle body coordinate system, and the lateral acceleration of the center of mass is obtained:

$$
\begin{aligned}
a_{y}= & v+u r-h \ddot{\phi} \sin \phi+2 h r \dot{\phi} \sin \phi \sin \theta- \\
& -2 h r \dot{\theta} \cos \phi \cos \theta-h \dot{r} \cos \phi \sin \theta-h r^{2} \sin \phi .
\end{aligned}
$$

Due to $\sin \theta \approx 0, \sin \phi \approx 0$, the Eq. (5) is simplified.

2.2. The moment equation of the vehicle body

Matrix Euler equation:

$$
J \dot{\omega}+\tilde{\omega} J \omega=M
$$

where $J$ is the inertia tensor matrix of the body in the satellite reference system, it can be represented as:

$$
J=\left[\begin{array}{ccc}
J_{11} & -J_{12} & -J_{13} \\
-J_{12} & J_{22} & -J_{23} \\
-J_{13} & -J_{23} & J_{33}
\end{array}\right]
$$

$\omega$ is the angular velocity coordinate array:

$$
\omega=\left[\begin{array}{lll}
p & q & r
\end{array}\right]^{T}, \dot{\phi}=p ; \quad \dot{\theta}=q ; \quad \dot{\gamma}=r ;
$$

$\tilde{\omega}$ is the antisymmetric coordinate matrix of $\omega$ :

$$
\tilde{\omega}=\left[\begin{array}{ccc}
0 & -r & q \\
r & 0 & -p \\
-q & p & 0
\end{array}\right] ;
$$

$M$ is the torque coordinate array:

$$
M=\left[\begin{array}{lll}
M_{x} & M_{y} & M_{z S}
\end{array}\right] .
$$

Substituting the Eqs.(7)-(9) into the Eq. (6), we can rearrange the equations.

Torque around the $x$ axis of the body:

$$
M_{x}=J_{11} \dot{p}-J_{13} \dot{r}-J_{13} p q-J_{22} q r+J_{33} q r .
$$

Torque around the $y$ axis of the body:

$$
M_{y}=J_{22} \dot{q}+J_{11} r p+J_{13} p^{2}-J_{13} r^{2}-J_{33} p r .
$$

Torque around the $z$ axis of the body:

$$
M_{z S}=J_{33} \dot{r}-J_{13} \dot{p}-J_{11} p q+J_{13} q r .
$$

2.3. Dynamic equations

The body vertical equation:

$$
m \ddot{z}=F_{s 1}+F_{s 2}+F_{s 3}+F_{s 4},
$$

where $F_{s i}(i=1,2,3,4)$ are the supporting forces of four suspensions.

$$
F_{s i}=k_{s i}\left(z_{i}-x_{i}\right)+c_{i}\left(\dot{z}_{i}-\dot{x}_{i}\right) \text {. }
$$

The vertical displacement of the upper end of the four suspensions can be obtained from the geometric relation in the Fig. 1 when there is a little roll angle and the pitching angle, we can get:

$$
\begin{aligned}
& x_{2}=z+a \theta-B_{f} \phi / 2 ; \\
& x_{2}=z+a \theta-B_{f} \phi / 2 ; \\
& x_{3}=z-b \theta+B_{r} \phi / 2 ; \\
& x_{4}=z-b \theta-B_{r} \phi / 2 .
\end{aligned}
$$

The vertical motion equation of four tires:

$$
m_{i} \ddot{z}_{i}=k_{t i}\left(q_{i}-z_{i}\right)-F_{s i}
$$

where $q_{i}$ is the vertical input of the ground, $k_{t i}$ is the tire stiffness.

The vehicle pitching movement equation:

$$
M_{y}=\left(F_{s 1}+F_{s 2}\right) a-\left(F_{s 3}+F_{s 4}\right) b+m g h \theta .
$$

The vehicle roll movement equation:

$$
M_{x}=\frac{B_{f}}{2}\left(F_{s 1}-F_{s 2}\right)+\frac{B_{r}}{2}\left(F_{s 3}-F_{s 4}\right) b+m g h \phi .
$$


The vehicle yaw angle movement equation:

$$
\begin{aligned}
M_{z}= & a\left(F_{y 1}+F_{y 2}\right) \cos \delta-b\left(F_{y 3}+F_{y 4}\right)+ \\
& +\left(F_{y 2}-F_{y 1}\right) \sin \delta+M_{1}+M_{2}+M_{3}+M_{4},
\end{aligned}
$$

where $M_{s i}(i=1,2,3,4)$ are the aligning torque of wheels, $F_{y i}(i=1,2,3,4)$ are the lateral forces of the left front, right front, left rear and right rear wheels of the vehicle.

The vehicle lateral force equation as follows:

$$
\left(m+\sum_{i=1}^{4} m_{i}\right) a_{y}=\left(F_{y 1}+F_{y 2}\right) \cos \delta+\left(F_{y 3}+F_{y 4}\right) \text {. }
$$

\subsection{The lateral force}

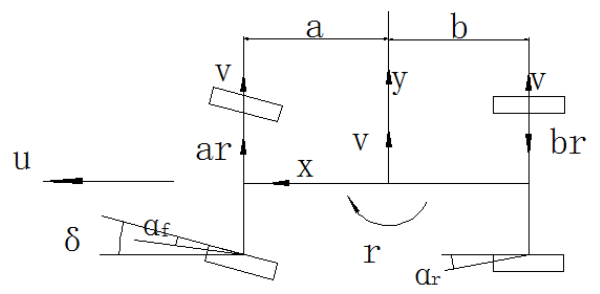

Fig. 2 The schematic diagram of vehicle steering Fig. 2.

The geometric relations are obtained from the

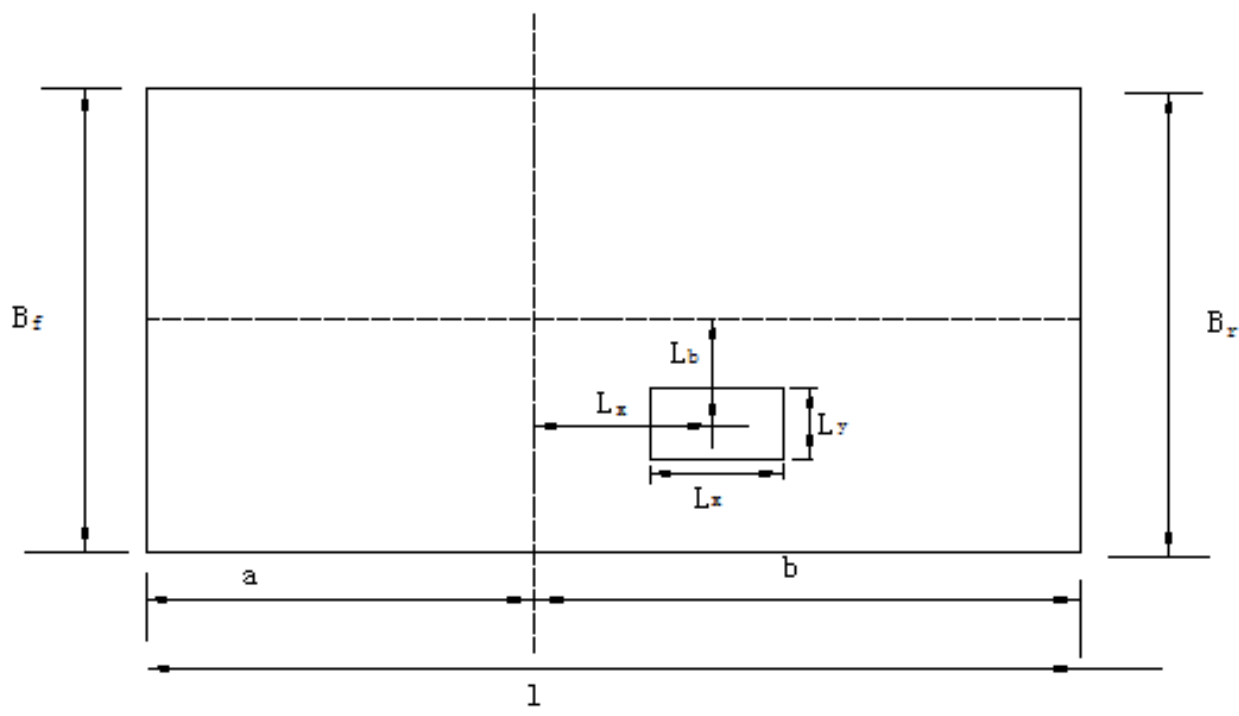

Fig. 3 Top view of model

The forces of four corners of the battery pack $F_{g i}(i=1,2,3,4)$ are shown as:

$$
F_{g i}=k\left(q_{g i}-z_{g i}\right)+c\left(\dot{q}_{g i}-\dot{z}_{g i}\right) .
$$

Regard the battery as four parts, there are:

$$
\frac{m \ddot{z}_{g i}}{4}-F_{g i}=0 \text {. }
$$

The geometric relations are obtained from the Fig. 3:
The front wheels side slip angle:

$$
a_{f}=\frac{v+a r}{u}-\delta
$$

The rear wheels side slip angle:

$$
a_{r}=\frac{v+b r}{u}
$$

Tyre side force:

$$
\begin{aligned}
& F_{y 1}=F_{y 2}=k_{a_{f}}\left(\frac{v+a r}{u}-\delta\right) ; \\
& F_{y 3}=F_{y 4}=k_{a_{r}} \frac{v+b r}{u} .
\end{aligned}
$$

2.5. The battery dynamics equation

Supposing the battery pack is a cuboid rigid body installed in the center of the chassis. The four corners of the cuboid bottom surface are used for fixing the devices in the body of the vehicle, which is regarded as four springs with elastic rigidity $k$. Due to the pitch, roll and vertical movement of the vehicle, the base, which is used for fixing battery springs, will be changed in the movement of the corresponding vertical direction, it can be considered as an input signal for the battery pack model, as shown in the Fig. 3.

$\mathrm{B}_{r}$

$$
\begin{aligned}
& q_{g 1}=z-\theta\left(L_{a}+L_{x} / 2\right)-\phi\left(L_{a}-L_{y} / 2\right) ; \\
& q_{g 2}=z-\theta\left(L_{a}+L_{x} / 2\right)-\phi\left(L_{a}+L_{y} / 2\right) ; \\
& q_{g 3}=z-\theta\left(L_{a}-L_{x} / 2\right)-\phi\left(L_{a}-L_{y} / 2\right) ; \\
& q_{g 4}=z-\theta\left(L_{a}-L_{x} / 2\right)-\phi\left(L_{a}+L_{y} / 2\right) .
\end{aligned}
$$

The vertical motion equation of the mass center of battery pack:

$$
m_{g} \ddot{z}_{g}-F_{g 1}-F_{g 2}-F_{g 3}-F_{g 4}=0 .
$$


The pitch motion equation of the battery pack:

$$
I_{g y} \ddot{\theta}_{g}+a_{g}\left(F_{g 1}+F_{g 2}\right)-b_{g}\left(F_{g 3}+F_{g 4}\right)=0 .
$$

The roll motion equation of the battery pack:

$$
I_{g x} \ddot{\phi}_{g}-B_{g f}\left(F_{g 1}-F_{g 2}\right) / 2-B_{g r}\left(F_{g 3}-F_{g 4}\right) / 2=0 .
$$

The vibration attenuation of battery can be calculated by the above equations under the circumstance of vehicle vertical input $q_{i}(i=1,2,3,4)$, vertical, roll and pitch motion of battery and vibration transmission of road surface.

\section{The establishment and calculation of roll simulation model}

Table 1 shows the parameters from a remodeled vehicle and its battery pack. White noise is the input signal for the simulation. Road roughness is the Power Spectral Density (PSD) Class E. The front wheels slowly turned $0.1 \mathrm{rad}$. The results are shown in Fig. 7-9.

Parameters of a 9-DOF vehicle model

\begin{tabular}{|c|c|c|}
\hline Parameters & Definition & Value \\
\hline$m, \mathrm{~kg}$ & Sprung Mass & 1173 \\
\hline$m_{1}, m_{2}, m_{3}, m_{4}, \mathrm{~kg}$ & Unsprung mass & 50 \\
\hline$J_{x x}, \mathrm{~kg} \mathrm{~m}^{2}$ & X axis moment of inertia & 1140 \\
$J_{y y}, \mathrm{~kg} \mathrm{~m}^{2}$ & Y axis moment of inertia & 3670 \\
$J_{z z}, \mathrm{~kg} \mathrm{~m}{ }^{2}$ & Z axis moment of inertia & 1900 \\
\hline$a, \mathrm{~m}$ & Front axle to the barycentre distance & 1.3 \\
$b, \mathrm{~m}$ & Rear axle to the barycentre distance & 1.58 \\
\hline Front wheel $B_{f}, \mathrm{~m}$ & Front axle width & 1.547 \\
Rear wheel $B r, \mathrm{~m}$ & Rear axle width & 1.554 \\
\hline$K_{s f}, \mathrm{~N} / \mathrm{m}$ & The front bearing spring stiffness & 24000 \\
$K_{s r}, \mathrm{~N} / \mathrm{m}$ & The rear bearing spring stiffness & 24750 \\
\hline$c_{f}, \mathrm{Ns} / \mathrm{m}$ & The front shock absorber damping & 3918 \\
$c_{r}, \mathrm{Ns} / \mathrm{m}$ & The rear shock absorber damping & 4310 \\
\hline$k_{t}, \mathrm{~N} / \mathrm{m}$ & Tire dynamic stiffness & 216000 \\
\hline$h, \mathrm{~m}$ & Roll axis to the barycentre distance & 0.3 \\
\hline$m_{b}, \mathrm{~kg}$ & Battery mass & 300 \\
\hline$I_{x x}, \mathrm{~kg} \mathrm{~m}{ }^{2}$ & X axis battery moment of inertia & 8.25 \\
$I_{y y}, \mathrm{~kg} \mathrm{~m}{ }^{2}$ & Y axis battery moment of inertia & 13 \\
\hline$k, \mathrm{~N} / \mathrm{m}$ & The battery pack holder stiffness & 500000 \\
\hline
\end{tabular}

\subsection{The establishment of simulation model}

Based on the simulation model, we respectively simulate the stability performances of the vehicle body roll model, the battery kinetic model and the full vehicle and the battery roll model on steady-state conditions of suspension parameters. Furthermore, we can model by using of Matlab/Simulink. It is shown as follows [10]-[12]:

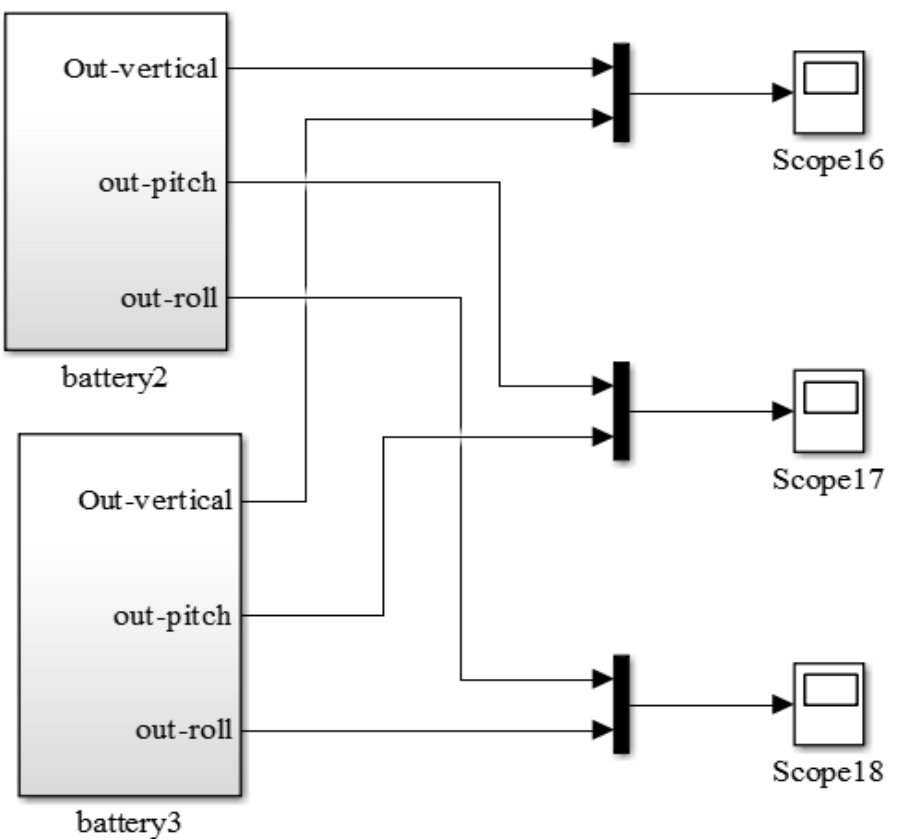

Fig. 4 The full vehicle and battery roll model 


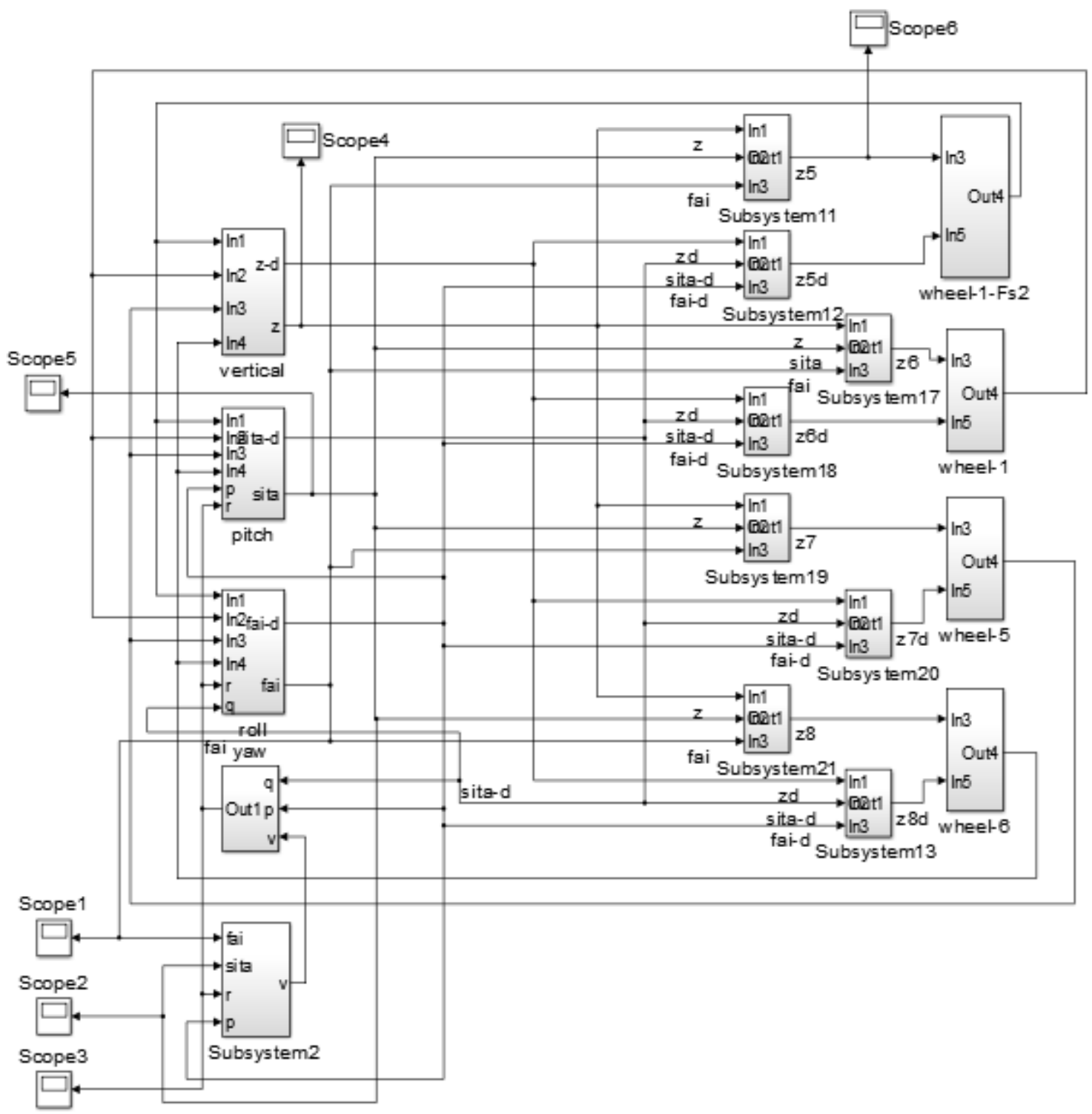

Fig. 5 Body roll model

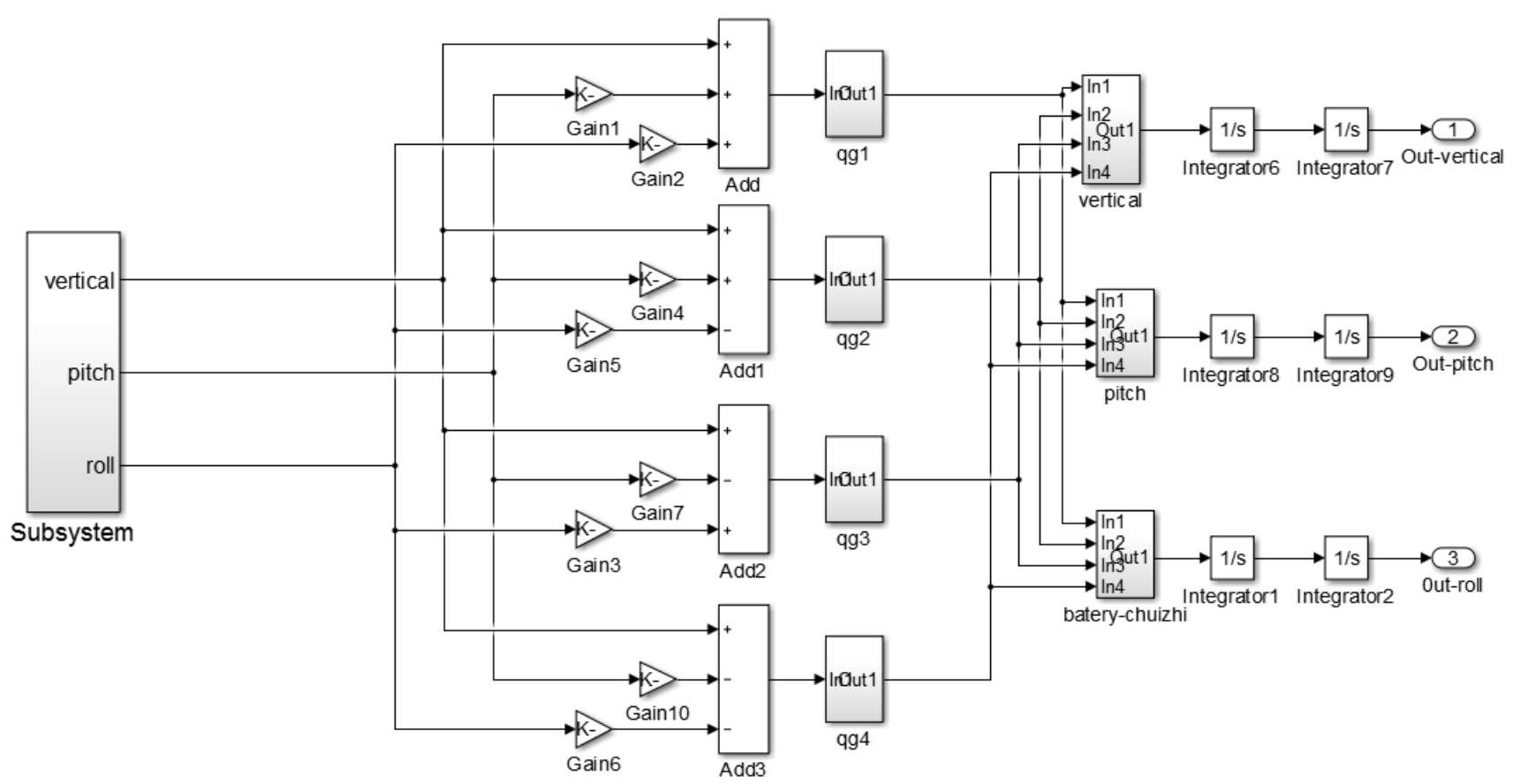

Fig. 6 Kinetic model of battery part 


\subsection{Simulation results}

There are three critical factors: battery pack vertical displacement, battery pack pitch angle and battery pack roll angle, which are emulated by same coordinate of the time, it is shown as Figs. 7-9. Based on the parameters of automotive layout and the size of battery pack, we changed vehicle suspension parameters and simulated again. Com- parison of simulation results after the suspension parameters changed as the Figs. 10-12 show. The results affect the battery pack stability and the design of suspension and battery pack parameters.

Fig. 7 shows the curve of battery pack vertical displacement, $\mathrm{X}$ coordinate axle represents time (s). Y coordinate axle represents battery pack vertical displacement $(\mathrm{m})$.

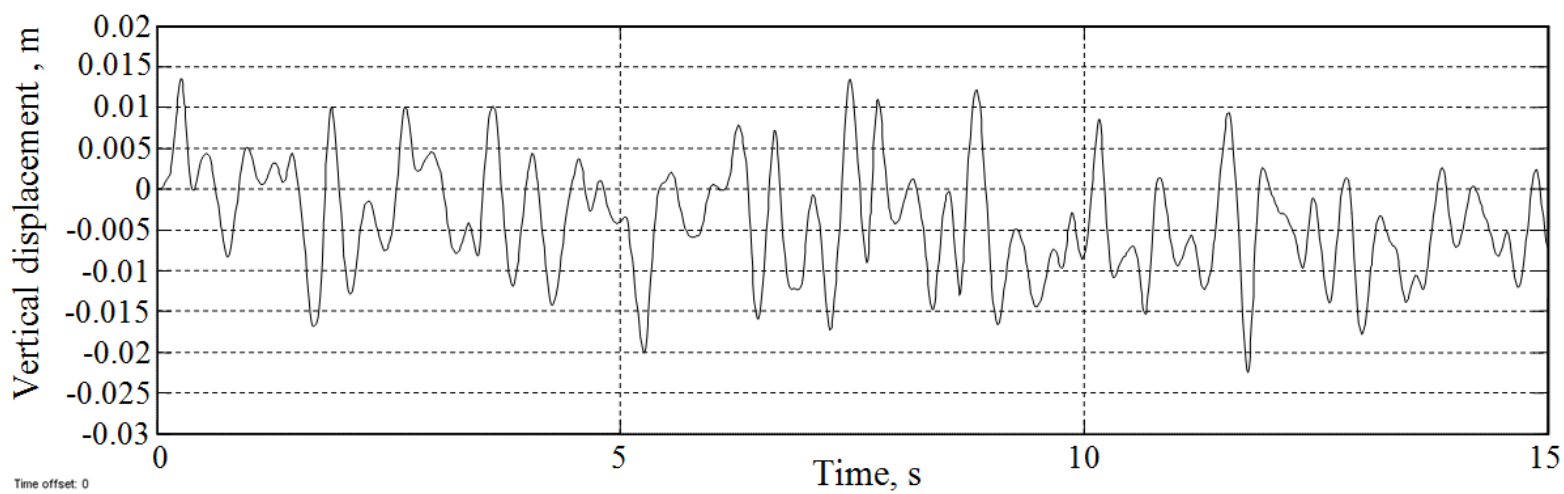

Fig. 7 Battery pack vertical displacement curve

Fig. 8 shows the curve of battery pack pitch angle, $\mathrm{X}$ coordinate axle represents time (s). Y coordinate axle represents battery pack pitch angle (rad).

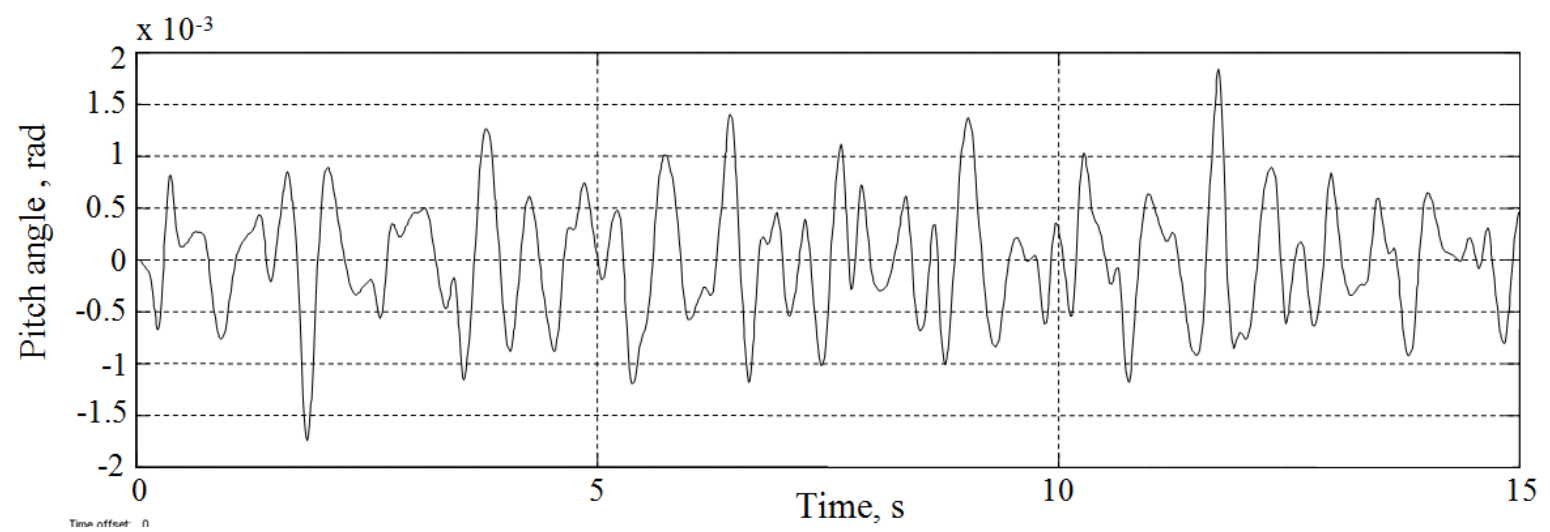

Fig. 8 Battery pack pitch angle curve

Fig. 9 shows the curve of battery pack roll angle, represents battery pack roll angle (rad). $\mathrm{X}$ coordinate axle represents time (s). Y coordinate axle

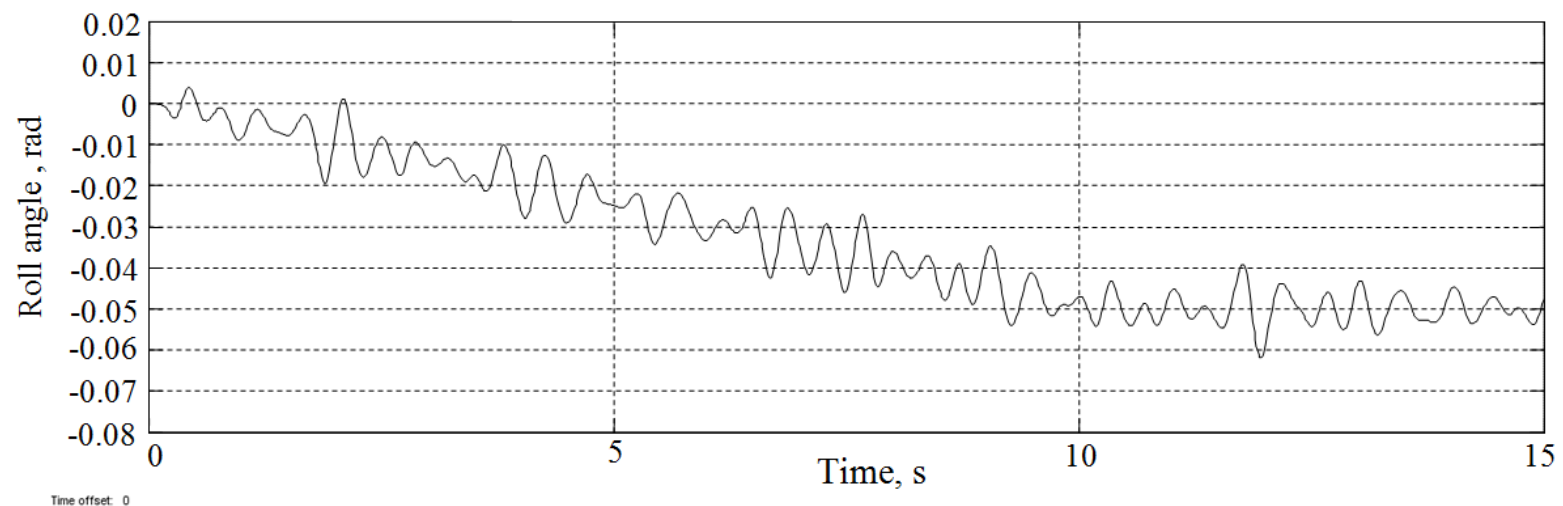

Fig. 9 Battery pack roll angle curve

The four suspensions stiffness values increased by $5000 \mathrm{~N} / \mathrm{m}$, the results are shown in Figs. 10-12. The dotted line in Figs. 10-12 stands for the situation after the suspen- sion rigidity has been raised and the solid line in Figs. 10-12 illustrate for the situation before the suspension rigidity has been raised. 


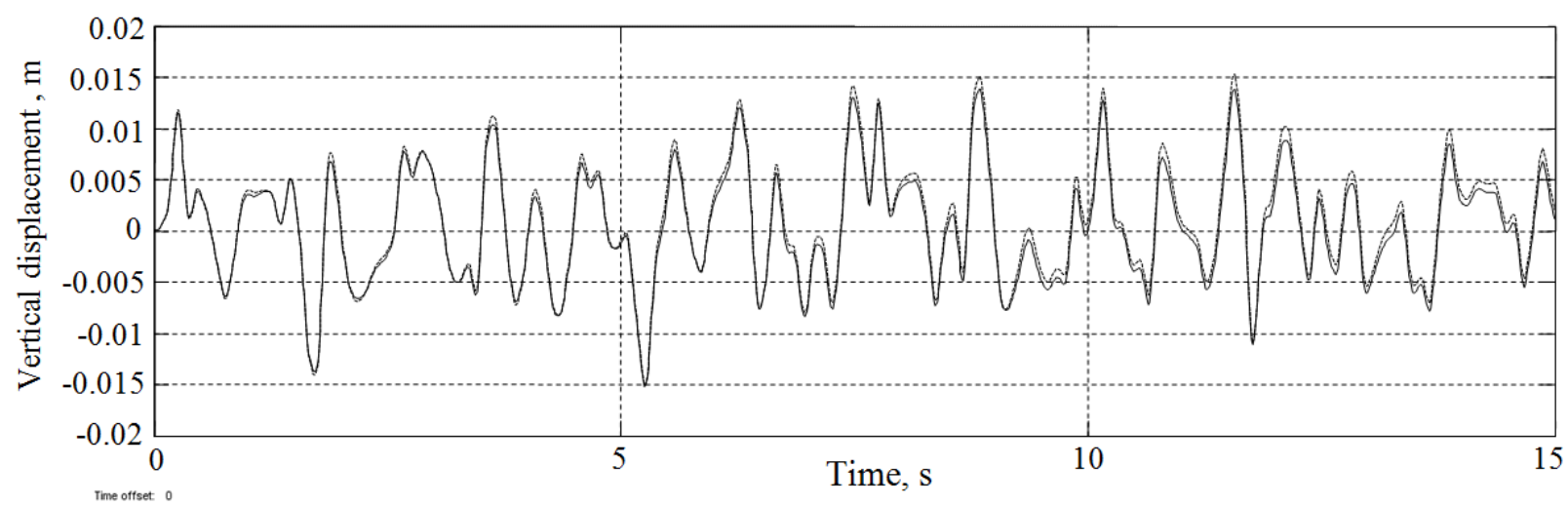

Fig. 10 comparison of vertical displacement of battery pack

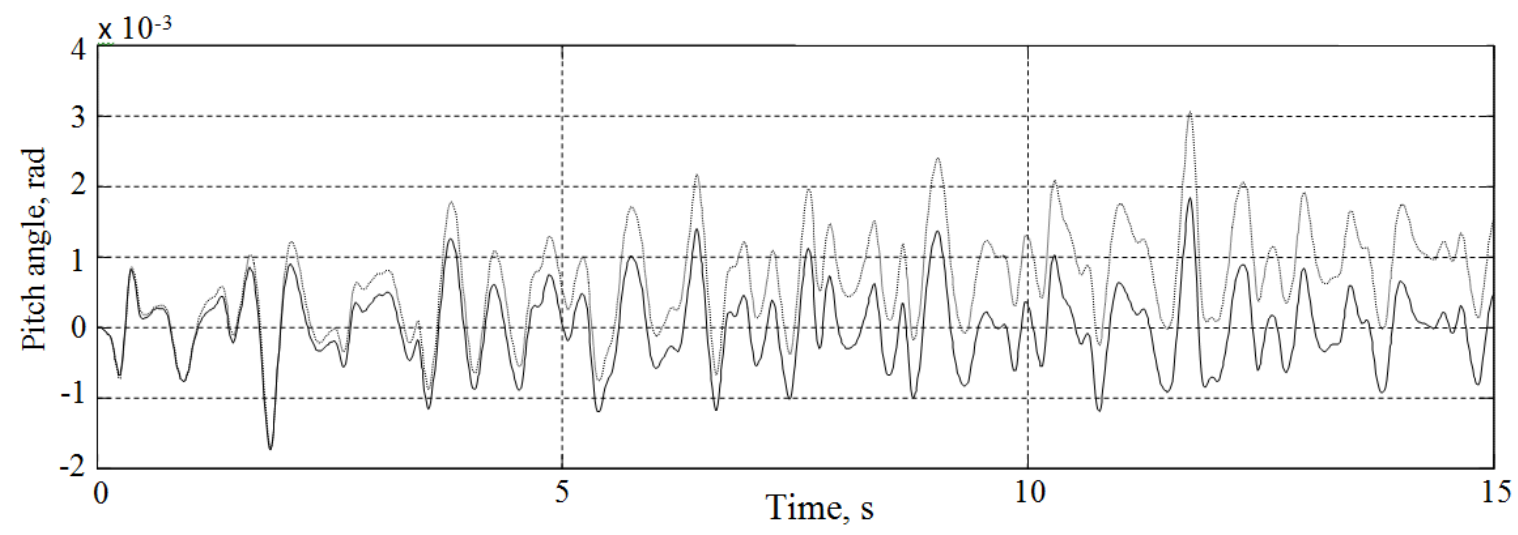

Fig. 11 comparison of the pitch angle of the battery pack

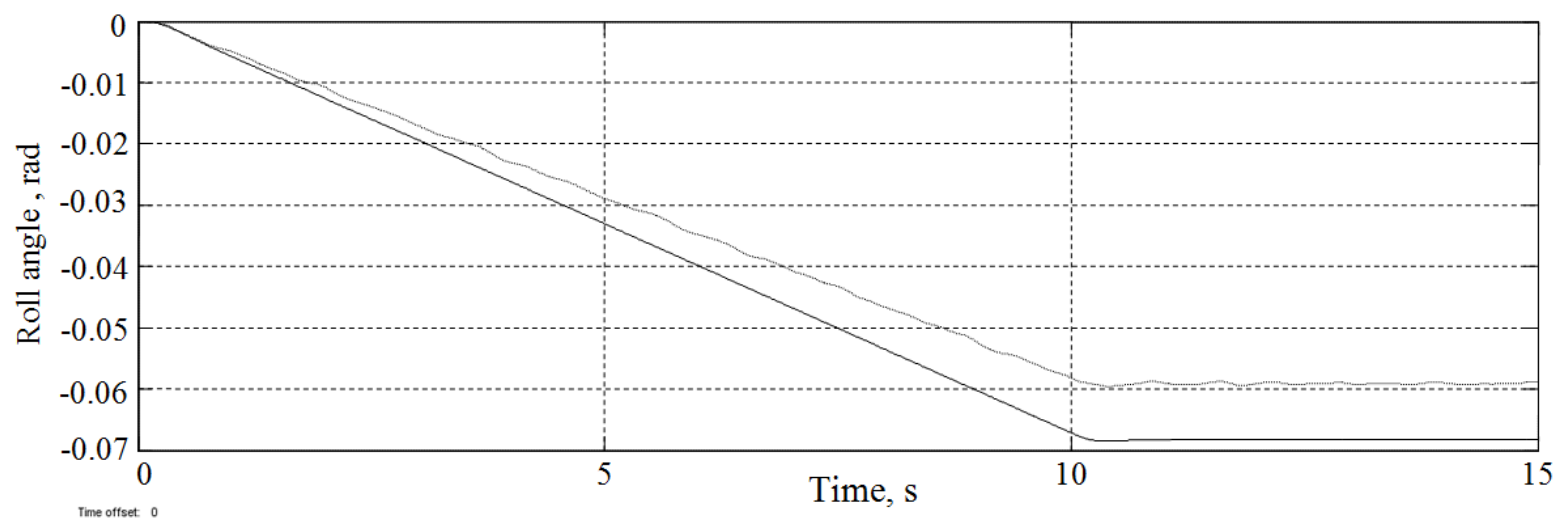

Fig. 12 Comparison of the roll angle of the battery pack

\subsection{Analysis of the model and results}

We can draw conclusions from the Figs. 7-9. When the steering angle slowly increases to a certain value, then the roll angle of the battery pack increases to a certain value too. It shows that the vehicle operates in a steady-state circular motion in stable state. If the speed of vehicle is not changed, then the battery pitch angle is unchanged. The vertical displacement of the battery changes little with the increase of the steering angle. It is because the steering angle is set to a smaller upper limit value during the simulation, and there is no large deviation in results.

And it can be known from Figs. 10-12, adding damping of front and rear suspensions will bulk up the vertical vibration amplitude of the battery, but the increment is relatively small. The pitch angle also increase, but in the meanwhile the roll angle has reduced, because the increase of suspension stiffness leads to the increase of roll angle stiffness. From the view of simulation results, the stiffness of the suspension is increased by configuring a high performance shock absorber and a short spring. Although it will inhibit roll, simply increasing the hardness of the shock absorber and spring will cause a lot of negative effects. On the one hand, the comfort of vehicles on the uneven roads is poor; on the other hand, as the suspensions cannot eliminate the road ups and downs, too many bounces of wheels lead to the loss of adhesion. So the stability of the battery pack has declined.

\section{Conclusions}

In this paper, the interaction of electric vehicle roll and battery pack stability was analyzed. When all of these impacts of automotive steering and vibration on body and battery pack are considered together, a full vehicle roll 
model of 9-DOF and Simulink model have been built to analysis the problem. The influence of the suspension parameters was simulated by increasing the four suspensions stiffness values. According to the calculated results, the suspension stiffness is a critical influence factor for the battery pack. When increased the four suspensions stiffness, the stability of the battery pack has declined. And the vibration is uncontrolled. Results obtained from this study are summarized as follows:

1. The stability of the vehicle body and the battery pack can reach an optimum value by the reasonable selection of the parameters of the suspension and the bracket;

2. Equipping vehicles with an active roll control system, a new type of suspension control system. It has become one of the hot spots in the development of automobile techniques.

\section{References}

1. Reza-Kashyzadeh, K.; Arghavan, A. 2014. Investigating the effect of road roughness on automotive component, Engineering Failure Analysis 41(3): 96-107. http://dx.doi.org/10.1016/j.engfailanal.2013.12.008.

2. Wang, M.L.; Jiang, F.C.; Zhang, Q. Song, S.N. 2014. Matching up the suspension of electric vehicle with the supporting system of battery pack, Mechanika 20(4): 382-389.

http://dx.doi.org/10.5755/j01.mech.20.4.6300.

3. Li, Q. 2009. The principle and maintenance of the vehicle dynamic driving anti roll stability control system, Motor For Repair \& Maintenance 11(12): 1-2.

4. Zhou, X.H. 2013. Research on vehicle stability modeling and control strategy based on yaw and roll, Doctoral dissertation, Chongqing University of Technology.

5. Kou, F.R. 2005. Computer simulation for coach handling dynamics with 14 DOFs, Journal of Xi'an University of Science and Technology 25(4): 507-510.

6. Mahmoodabadi, M.J.; Safaie, A.A.; Bagheri, A.; Nariman-Zadeh, N. 2013. A novel combination of particle swarm optimization and genetic algorithm for pareto optimal design of a five-degree of freedom vehicle vibration model, Applied Soft Computing 13(5): 2577-2591.

http://dx.doi.org/10.1016/j.asoc.2012.11.028.

7. Wang, G.Y.; Zhang, J.L. 2011. Research on the stability performances of the vehicle dynamics equivalent system based on the unsteady constraints, Mechanika 5(5): 518-522. http://dx.doi.org/10.5755/j01.mech.17.5.729.

8. Marofi, S.Ms.; Seyedalian, S.J.; Akram, L. 2013. Improve active suspension system by FEL controller design, Mechanika 77(6): 681-687. http://dx.doi.org/10.5755/j01.mech.19.6.6010.

9. Yu, Z.S. 2005. The Theory of Automobile, fifth edition, Beijing: China Machine Press.

10. Shim, T.; Velusamy, P. 2011. Improvement of vehicle roll stability by varying suspension properties, Vehicle System Dynamics International Journal of Vehicle Mechanics \& Mobility 49(1): 129-152.

http://dx.doi.org/10.1080/00423111003615196.

11. Tseng, H.E.; Xu, L.; Hrovat, D. 2007. Estimation of land vehicle roll and pitch angles, Vehicle System Dynamics 45(5): 433-443. http://dx.doi.org/10.1080/00423110601169713.

12. Miege, Arnaud J.P.; Cebon, D. 2005. Optimal roll control of an articulated vehicle: theory and model validation, Vehicle System Dynamics 43(12): 867-884. http://dx.doi.org/10.1080/00423110500217167.

Yuezhen Fan, Jie Sun

\section{STUDY ON THE INTERACTION OF ELECTRIC VEHICLE ROLL AND BATTERY PACK STABILITY}

S u m m a r y

As a key factor for the safety of electric vehicles, electric vehicles are focused on battery pack stability rather than vehicle dynamics. The stability of battery pack depends on the performance of suspensions and battery supporting system. Automobile suspensions can reduce the bumps and vibrations that come from road unevenness. Its purposes are to prevent the shock and vibration from transferring to the body, and reduce the vibration of the battery pack. To improve the performance of suspension systems of the electric vehicle and the stability of battery pack, the paper proposes a study on the interaction of electric vehicle roll and battery pack stability. 9-DOF vehicle vibration and roll model was established based on analysis of movement of the battery pack. Then simulation model was established to check the result to get the reasonable suspension stiffness by using Matlab/Simulink. The results show that the stiffness of the suspension is increased by configuring a high performance shock absorber and a short spring. Although it will inhibit roll, simply increasing the hardness of the shock absorber and the spring will cause a lot of negative effects.

Keywords: roll, vibration, stability, battery pack, electric vehicle.

Received January 29, 2016 Accepted February 06, 2017 